\title{
ВРОЖДЕННЫЙ ПОРОК СЕРДЦА ПРИ СИНДРОМЕ МИКРОДЕЛЕЦИИ 22 ХРОМОСОМЫ: КЛИНИЧЕСКОЕ НАБЛЮДЕНИЕ
}

\author{
( Ворвуль А.О., Кривдина Н.Д., Хмелевская И.Г., Матвиенко Е.В.
}

\author{
Курский государственный медицинский университет (КГМУ) \\ Россия, 305041, Курская область, г. Курск, ул. К. Маркса, д. 3
}

\begin{abstract}
Синдром делеции 22-й хромосомы (синдром Ди Джорджи) - это совокупность морфологических, иммунологических и неврологических изменений, которые являются следствием del22q11.2. В типичном случае данная патология представляет собой триаду симптомов, включающую: врожденный порок сердца, гипо- или аплазию вилочковой железы и гипокальциемию, как следствие гипоплазии паращитовидной железы. Синдром Ди Джорджи изменчив в своих проявлениях и степени их выраженности, что объясняет тот факт, что этот синдром имеет несколько названий, наиболее известными из которых являются велокардиофациальный сидром, синдром Шпринтцен, синдром Кайлера. В статье описан клинический случай врожденного порока сердца у ребенка 8 месяцев, у которого был диагностирован синдром микроделеции 22 хромосомы, его основные клинические проявления, особенности диагностики и методы лечения. Тактика ведения пациента с синдромом Ди Джоржи должна быть соответствующей клиническим рекомендациям и стандартам оказания медицинской помощи и быть ориентированной не только на хирургическое коррекцию врожденного порока сердца, но и на своевременную стабилизацию Т-клеточного звена иммунитета, предупреждение рецидивов инфекционных заболеваний, что способствует благоприятному течению болезни, улучшению качества жизни пациентов и определяет благополучный прогноз в будущем.
\end{abstract}

Ключевые слова: синдром Ди Джорджи; делеция 22q11.2; врожденные пороки сердца; дети; хромосомные болезни.

Ворвуль Антон Олегович - студент, КГМУ, г. Курск. ORCID iD: 0000-0002-1529-6014. E-mail: vorvul1996@mail.ru (автор, ответственный за переписку)

Кривдина Нина Дмитриевна - ассистент кафедры педиатрии, КГМУ, г. Курск. E-mail: dvoinyh.nina@yandex.ru

Хмелевская Ирина Григорьевна - д-р мед. наук, профессор, зав. кафедрой педиатрии, КГМУ, г. Курск. ORCID iD: 00000002-9159-5702. E-mail: khmig@yandex.ru

Матвиенко Елена Витальевна - канд. мед. наук, ассистент кафедры педиатрии, КГМУ, г. Курск. E-mail: tabletka-2013@mail.ru

Синдром Ди Джорджи (СДД) является врожденным заболеванием иммунной системы, которое клинически определяется как первичный иммунодефицит с поражением Т-клеточного звена иммунитета в сочетании с а- или гипоплазией паращитовидных желез, врожденными пороками сердца (ВПС) и частым выявлением дисморфизма лицевой части черепа. У большинства пациентов происходят задержка физического и психомоторного развития, нарушение когнитивных функций. Данная нозология впервые была описана американским педиатромэндокринологом Di George Angelo Mario в 1965 году

По результатам множественных молекулярных и цитогенетических исследований было определено, что del22q11.2 является ведущим этиологическим фактором СДД и встречается спорадически более чем в $90 \%$ случаев. Анализ образцов ДНК пациентов выявил, что в 85-90\% случаев выпадающий участок является одним и тем же. Хромосомная мутация определяется между участками D22S427 на 22q11.21 и D22S801 на 22q11.23. Работы последних лет, посвященные СДД, свидетельствуют о многообразии мутаций при такой комбинации клинических про- явлений. Описаны случаи симптомокомплекса СДД при локализации делеции и в других хромосомах - 10p13, 17p13, 18q21. По данным литературы, до 5\% детей с ВПС имеют такую хромосомную аномалию.

Данная патология встречается у одного из 4000-6000 новорожденных, половой и этнической предрасположенности к СДД не наблюдается $[2,3]$.

В результате del22q11.2 нарушается внутриутробное развитие третьего и четвертого глоточных карманов, из которых на шестой неделе внутриутробного развития в норме формируются вилочковая и паращитовидные железы. Кроме того, поражаются соседние органы, что выражается дисморфизмом лица: гипоплазией нижней челюсти, расщепление неба и верхней губы, низким расположением, деформацией ушных раковин и другими дефектами. У $2 / 3$ детей с СДД диагностируются ВПС - дефект межжелудочковой перегородки, тетрада Фалло, открытый боталлов проток, дупликация дуги аорты, коарктация аорты. Диагностика данных пороков возможна еще в периоде внутриутробного развития плода при проведении ультразвукового исследования $[1,2]$. 
Диагноз ставится на основе клинической картины и данных лабораторных исследований. Наиболее частым клиническим проявлением заболевания является гипопаратиреоз, в связи с чем наиболее частым дебютом СДД являются тонико-клонические судороги в периоде новорожденности вследствие развития гипокальциемии. Длительная гипокальциемия является причиной нарушения роста и развития ребенка, патологии костной системы, множественного кариеса зубов. В более позднем периоде жизни она может стать причиной вторичного синдрома удлиненного интервала Q-T, желудочковых аритмий и внезапной коронарной смерти $[7,8]$. Таким образом, на прогноз течения СДД оказывает влияние уровень выраженности дефектов сердечно-сосудистой и эндокринной систем и степень иммунодефицита.

Лечение СДД направлено на корригирование осложнений, возникающих в определенные моменты жизни пациента, большинство детей требуют оперативного вмешательства различной степени.

В качестве примера приводится клинический случай синдрома Ди Джорджи.

Девочка Ю., 2018 года рождения, находилась на стационарном лечении в 3 педиатрическом отделении областной детской клинической больницы с 26.09.18 г. по 05.10.18 г.

Ребенок от молодых здоровых родителей, наследственность по СДД и ВПС не отягощена. ВПС, синдром микроделещии 22 хромосомы выявлен на 22 неделе беременности, от прерывания беременности мать отказалась. Ребенок от 1 беременности, протекавщей с угрозой прерывания на 21 неделе, от 1 срочных родов. Вес при рождении - 3040 г, рост - 51 см, оценка по шкале Апгар 6-7 баллов. Поведена тактильная стимуляция, кислородотерапия маской, переведена в отделение реанимации и интенсивной терапии (ОРИТ), с 1 суток начато энтеральное питание, инфузия простагландина E, антибактериальная терапия- ампициллил+сульбактам $75 \mathrm{Mz} / \kappa 2 / с у \mathrm{~mm}$ внутривенно.

Реанимационной бригадой скорой помощи переведена в Научный медицинский исследовательский центр сердечно-сосудистой хирургии им. Бакулева (НМИЦ ССХ им. Бакулева) для проведения оперативного вмешательства.

При поступлении в НМИЦ ССХ им. Бакулева объективно: общее состояние крайне тяжелое. Вес - 3000 г (-40 г), рост - 51 см. Кожные покровы бледные, видимые слизистые бледно-розовые. Влажность кожи нормальная. Размеры большого родничка 0,5 х 0,5 см. Грудная клетка правильной формы, равномерно движется при дыхании. Дьхание глубокое, ритмичное. В легких дыхание пуэрильное, хрипов нет, ЧД - 64 в/мин, SpO2 - 98\%.
Тоны сердиза ритмичные, I тон нормальный, II тон усиленный, ЧСС - 148 в/мин, АД - 80/40 мм pm. cm. Живот мягкий, безболезненный при пальпации. Нижний край печени выступает на 3,5 см из-под края реберной дуги, селезенка не пальпируется. Стул, диурез в норме. Глаза открывает, реакиия зрачков на свет живая.

По данным электрокардиографии (ЭКГ) (18.07.2018): ритм синусовый, ЧСС - 162 в/мин, электрическая ось сердиа отклонена вправо, $P Q$ - 0,11c, $Q R S-0,09 c, Q R S T-0,28 c$.

При проведении R-графии органов грудной клетки (от 17.07.2018): тень сердиа шаровидной формы, отечный синдром, кардиопатия.

Эхокардиография (18.07.2018): левый желудо-

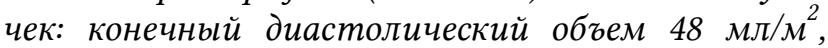
конечный диастолический размер 1,8 см, фракиия выброса 66\%. Митральный клапан - створки подвижные, фиброзное кольцо 12,8 мм (N-11,2 мм), регургитация 1+. Аортальный клапан - двустворчатый, раскрытие полное, фиброзное кольцо 7 мм (N- 7 мм). Правый желудочек и правое предсердие увеличены. Клапан легочной артерии не изменен, фиброзное кольцо 11 мм ( $N-8$ мм), регургитачия 1+. Легочная артерия расширена. Трикуспидальный клапан - створки удлинень, фиброзное кольио 14,3 мм (N - 13 мм), регургитаиия 1+. Перимембранозный дефект межжелудочковой перегородки 8 мм, иентральный дефект межпредсердной перегородки II типа 7-8 мм, митральный порок сердиа 1,6 мМ, открытый аортальный проток 8 мМ.

Учитывая анатомию дуктус-зависимого ВПС, критическое состояние пациента, было принято решение о проведении оперативного лечения ВПС.

23 июля 2018 года произведена операщия по устранению перерыва дуги аорты, пластики дефекта межжелудочковой перегородки ксеноперикардиальной заплатой, уменьшение размеров дефекта межпредсердной перегородки, в условиях искусственного кровообращения, гипотермии и фармакохолодовой кристаллоидной кардиоплегии.

Послеоперащионный период осложнился сердечно-легочной недостаточностью $u$ ИВЛ-зависимой пневмонией.

Проведено лечение: вазопрастан, адреналин с 23.07-20.08.18, нанипрус 1 мг/кг/сут 23.07-18.08.18, верошпирон $4 \mathrm{mz} / \mathrm{kz} /$ сут, фуросемид 1-2 мг/кг/сут, неоднократное переливание эритроцитарной массы и свежезамороженной плазмы 23.07, 31.07, 10.08, дексаметазон 0,3 мгкг/сут, антибактериальная терапия: ампищиллин+сульбактам

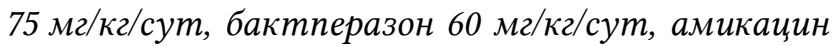
$20 \mathrm{mz} / \kappa 2 / с у$ су, полимиксин В 1,5 мг/кг/сут, иефта-

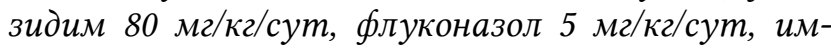
муноглобулин № $31 \mathrm{мл/к2/сутm.}$

При лабораторном исследовании отмечались снижение гемоглобина (Нb) до 103 г/л, эритроци- 
тов до 3,32 × $10^{12} / л$, дисфункция гепатобилиарного тракта за счет повышения уровня аспартамаминотрасферазы (АСТ) до 153 Ед/л.

Было проведено инструментальное иссследование: ЭКГ (23.08.18) - ритм синусовыц с ЧСС - 152 в/мин, холтеровское мониторирование (02.09.18) - синусовыци ритм со среднесуточной ЧСС- 143 в/мин, преходящая синоатриальная блокада 3 степени, зафиксировань 44 экстрасистолы, $R$-графия органов грудной клетки (27.08.18): жидкости в плевральной полости нет, небольшое усиление легочного рисунка; эхокардиография (27.08.18) - жидкости в перикардиальной полости нет, фракция выброса левого желудочка 64\%, заплата фиксирована, реканализация верхнего края заплать - 2,6 мм.

Учитьвая стабилизацию состояния для дальнейшего лечения ребенок в сопровождении реанимационной бригады переведена в ОРИТ ОДКБ.

При первичном осмотре в стационаре: общее состояние тяжелое, температура тела в норме. Кормится через зонд смесью Фрисолак по 60 мл через каждые 3 часа. Положение тела активное. Вес - 3150 гр (прибавка 150 г), рост - 54 см, белково-энергетическая недостаточность 3 степени (дефецит веса 35\%), развитие гармоничное. Кожные покровы, видимые слизистые бледные с мраморным рисунком, послеоперационный шов в области грудинь. Влажность кожи нормальная. Тургор тканей удовлетворительный. Тонус мыши снижен. Грудная клетка деформирована воронкообразная, диспластическая, равномерно движется при дыхании. Дыхание глубокое, ритмичное. В легких дыхание жесткое, хрипь проводнье, ЧД - 52 в/мин, $\mathrm{SpO}_{2}$ - 98\%. Тоны сердца ритмичные, ЧСС - 127 в/мин, АД - 80/40 мм pm. cm. Жuвот мягкий, безболезненный при пальпации. Печень на 1,5 см выступает из-под края реберной дуги, селезенка не пальпируется. Стул, диурез в норме.

При проведении динамического лабораторного исследования отмечается нормализация уровня Нb (114-121 г/л), при оценке кислотно-щелочного состояния выявлен ацидоз за счет рН - 7,204, pCO $\mathrm{CO}_{2}-49,8$ мM pm. cm., $\mathrm{pO}_{2}-44,9$ мM pm. cm., $\left[\mathrm{HCO}_{3}^{-}\right]$- 19,8 ммоль/л, ВEесf - 8,4 ммоль/л, SВC-17,7 ммоль/л, ВE 6 - 7,8 ммоль/л.

По данным УЗИ сердия: АК 7,0 мм, створки не изменены, смыкание полное. Дуга аорты без особенностей. МГД на перешейке 7,5 мм рт. cm. Поперечная дуга аорты 8 мм. Клапан легочной артерии 12 мм, створки пролабируют, смыкание недостаточное. Митральныц клапан 13 мм створки не изменены, смыкание полное. Трикуспидальный клапан - 13 мм, створки утолщены по свободному краю, пролабируют, смыкание недостаточное. Регургитация 3+. Клапан легочного ствола не изменен. Среднее систолическое давле- ние на легочном стволе 40 мм рm. cm. Межпредсердная перегородка: 2 межпредсердных соустья по 1 мм в области овальной ямки. Межжелудочковая перегородка иелостная. Гипертрофии миокарда нет. Перикард не изменен. Конечный диастолический размер правого желудочка 11 мм, Конечный диастолический размер левого желудочка 23 мм. Конечный систолический размер левого желудочка 16 мм. Размер левого предсердия 16 мм. Дополнительных образований в сердие нет. Фракиия выброса 61\% (снизилась на 5\%), фракция укорочения 31\%. толщина межжелудочковой перегородки 3,0 мм, толщина задней стенки левого желудочка 4,0 мм, толщина передней стенки правого желудочка 3,0 мм. Заключение: митральный порок сердиа, умеренное сужение дуги аорты, недостаточность клапана легочной артерии, недостаточность трикуспидального клапана. Умеренная объемная перегрузка всех камер сердца, преимущественно левого желудочка и правого предсердия.

Осмотрена кардиологом (05.10.18), была произведена коррекция терапии.

Проведено лечение: фрисолак 70 мл 8 раз в день, интенсивная терапия 26.09.18, кислородотерапия через носовые канюли 0,5 л/мин 26.09.18, верошпирон 6 мг 2 раза в день, фуросемид 2 мг 2 раза в день, аспаркам 1/4 таблетки 2 раза в день, азитромицин 0,8 мл 2 раза в день.

На фоне лечения общее состояние улучшилось, отмечалась прибавка в весе 140 г, питание удерживала, не срыгивала. В легких дыхание пуэрильное, хрипов нет, ЧД - 33 в/мин, тоны сердияа ритмичные, короткий систолический шум слева от грудины, ЧСС - 120 в/мин, АД - 80/50 мм pm. cm., $\mathrm{SpO}_{2}-96 \%$. Ребенок был вылисан в удовлетворительном состоянии.

Таким образом, у данного пациента наблюдалось серьезное проявление синдрома микроделеции 22 хромосомы - врожденный порок сердца. В таком случае показано только оперативное лечение в кратчайшие сроки после рождения, что кардинально улучшает продолжительность и качество жизни пациента, но не гарантирует полного выздоровления, так как при СДД в первую очередь поражается иммунная система. Поэтому в перспективе необходимы динамическое наблюдение показателей активности Т-клеточного звена иммунитета и его коррекция при обнаружении патологических изменений.

\section{КОНФЛИКТ ИНТЕРЕСОВ}

Авторы декларируют отсутствие явных и потенциальных конфликтов интересов, связанных с публикацией настоящей статьи. 
Ворвуль А.О. - анализ и интерпретация данных, Кривдина Н.Д., Матвиенко Е.В. - проверка критически важного интеллектуального содержания, Хмелевская И.Г. - окончательное утверждение для публикации рукописи.

\section{ИСТОЧНИКИ ФИНАНСИРОВАНИЯ} ния.

Авторы заявляют об отсутствии финансирова-

\section{СООТВЕТСТВИЕ ПРИНЦИПАМ ЭТИКИ}

Законный представитель (мать) рассматриваемого пациента подписал информированное согласие на публикацию результатов обследования и лечения.

\section{ЛИТЕРАТУРА/REFERENCES}

1. Намазова-Баранова Л.С., Гинтер О.В., Полунина Т.А., Давыдова И.В., Савостьянов К.В., Пушков А.А., Журкова Н.В., Мосьпан Т.Я. Синдром делеции 22q11.2: симптомы, диагностика, лечение. Вопросы современной педиатрии. 2016; 15(6):529-534 [Namazova-Baranova L.S., Ginter O.V., Polunina T.A., Davydova I.V., Savost'yanov K.V., Pushkov A.A., ZHurkova N.V., Mos'pan T.Ya. Deletion 22q11.2 syndrome: symptoms, diagnosis, treatment. Voprosy sovremennoy pediatrii. 2016; 15(6):590595. (in Russ.)]. DOI: 1010.15690/vsp.v15i6.1656

2. Разживин С.А., Демяшкина М.С., Радаева О.А., Новикова Л.В., Измайлова Э.Э. Синдром
Ди Джорджи - сложный клинический диагноз. Трудный пациент. 2018; 16(1-2):32-35 [Razzhivin S.A., Demyashkina M.S., Radayeva O.A., Novikova L.V., Izmaylova E.E. Di George Syndrome is a Complex Clinical Diagnosis. Trudnyy patsiyent. 2018; 16(1-2):32-35 (in Russ.)]

3. Caroline Y. Kuo, Singer R., Sulagna C.S. Immune and Genetic Features of the Chromosome 22q11.2 Deletion (DiGeorge Syndrome). Current Allergy and Asthma Reports. 2018; 18:e75. DOI: 10.1007/s11882018-0823-5

4. Chikkabyrappa S., Mahadevaiah G., Buddhe S., Alsaied T., Tretter J. Common Arterial Trunk: Physiology, Imaging, and Management. Semin Cardiothorac Vasc Anesth. 2018; 29:e1089253218821382. DOI: $10.1177 / 1089253218821382$

5. Morrow B.E., McDonald-McGinn D.M., Emanuel B.S., Vermeesch J.R., Scambler P.J. Molecular genetics of 22q11.2 deletion syndrome. Am J Med Genet A. 2018; 176(10):2070-2081. DOI: 10.1002/ajmg.a.40504

6. Rayannavar A., Levitt Katz L.E., Crowley T.B., Lessig M., Grand K., Goldmuntz E., Zackai E.H., McDonald-McGinn D.M. Association of hypocalcemia with congenital heart disease in 22q11.2 deletion syndrome. Am J Med Genet A. 2018; 176(10):2099-2103. DOI: 10.1002/ajmg.a.40495

7. Sullivan K.E. Chromosome 22q11.2 deletion syndrome and DiGeorge syndrome. Immunology Review. 2019; 287(1):186-201. DOI: 10.1111/imr.12701

Поступила в редакцию 01.03.2019 Подписана в печать 19.09.2019

Для цитирования: Ворвуль А.О., Кривдина Н.Д., Хмелевская И.Г., Матвиенко Е.В. Врожденный порок сердца при синдроме микроделеции 22 хромосомы: клиническое наблюдение. Курский научно-практический вестник «Человек и его здоровье». 2019; (3):41-45. DOI: 10.21626/vestnik/2019-3/06.

\title{
CONGENITAL HEART DESEASE IN CHROMOSOME 22 MICRODELETION SYNDROME: CLINICAL OBSERVATION
}

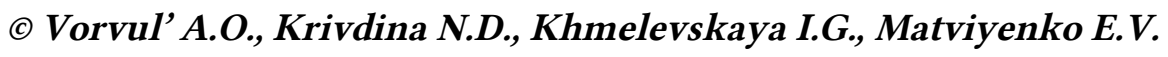

Kursk State Medical University (KSMU)

3, K. Marx St., Kursk, Kursk region, 305041, Russian Federation

\begin{abstract}
The chromosome 22q11.2 deletion (DiGeorge Syndrome) is a set of morphological, immunological and neurological changes that are a consequence of 22q11.2 deletion. In a typical case, this pathology is a triad of symptoms, including: congenital heart disease, hypoplasia or aplasia of the thymus gland and hypocalcemia which is a consequence of hypoplasia of the parathyroid gland. DiGeorge syndrome is variable in its manifestations and the degree of its severity, which explains the fact that this syndrome has many names, the most famous of which are Sprintzen syndrome, Kyler's syndrome, facial and conotruncal abnormalities. The article describes a clinical case of congenital heart disease in a child of 8 months, who was diagnosed with 22 chromosome microdeletion syndrome, its main clinical manifestations, features of diagnosis and treatment methods. The tactics of managing a patient with DiGiorge syndrome should meet the standards and be focused not only on surgical elimination of the defect from the heart, but also on therapy aimed at timely stabilization of the immune response, prevention of repeated infectious diseases which contributes to the favorable course of the disease and determines a successful prognosis in the future.
\end{abstract}

Keywords: DiGeorge syndrome; 22q11.2 deletion; congenital heart disease; children; chromosomal abnormalities.

Vorvul' Anton O. - Student, KSMU, Kursk, Russian Federation. ORCID iD: 0000-0002-1529-6014. E-mail: vorvul1996@mail.ru (correspondence author) 
Курский научно-практический вестник "Человек и его здоровье". - 2019. - № 3.

Krivdina Nina D. - Assistant of Department of Pediatrics, KSMU, Kursk, Russian Federation. E-mail: dvoinyh.nina@yandex.ru

Khmelevskaya Irina G. - DM, Professor, Head of Department of Pediatrics, KSMU, Kursk, Russian Federation. ORCID iD: 00000002-9159-5702. E-mail: khmig@yandex.ru

Matviyenko Elena V. - $\mathrm{PhD}$ in Medicine, Assistant of Department of Pediatrics, KSMU, Kursk, Russian Federation. E-mail: tabletka-2013@mail.ru

\section{CONFLICT OF INTEREST}

The authors declare the absence of obvious and potential conflicts of interest related to the publication of this article.

\section{AUTHORS CONTRIBUTION}

Vorvul A.O. - data analysis and interpretation, Krivdina N.D., Matvienko E.V. - substantiation of the article and verification of critical intellectual content, Khmelevskaya I.G. - final approval for the article publication.

\section{SOURCE OF FINANCING}

The authors state that there is no funding for the study.

\section{CONFORMITY WITH THE PRINCIPLES OF ETHICS}

The legal representative (mother) of the patient in question has signed an informed consent to publish the results of the examination and treatment.

For citation: Vorvul' A.O., Krivdina N.D., Khmelevskaya I.G., Matviyenko E.V. Congenital heart desease in chromosome 22 microdeletion syndrome: clinical observation. Kursk Scientific and Practical Bulletin "Man and His Health". 2019;(3):41-45. DOI: $10.21626 /$ vestnik/2019-3/06. 